\title{
A Theory of Gamification Principles Through Goal-Setting Theory
}

\author{
Gustavo F. Tondello \\ University of Waterloo, Canada \\ gustavo@,tondello.com
}

\author{
Hardy Premsukh \\ FlourishiQ Inc., Canada \\ hpremsukh@,flourishiq.com
}

\author{
Lennart E. Nacke \\ University of Waterloo, Canada \\ lennart.nacke@acm.org
}

\begin{abstract}
Goal-setting theory has been used for decades to explain how to motivate people to perform better in work-related tasks, but more recently gamification has also gained attention as an alternative method to increase engagement and performance in many contexts. However, despite goals and feedback being common elements of gameful implementations, there is a lack of literature explaining how gamification works through the lens of goal-setting theory or suggesting how goalsetting concepts and recommendations can be employed to improve gameful systems. Therefore, we present a literature review and a conceptual framework that establishes a relationship between goal-setting and gamification concepts. Next, we describe how this framework can help explain gamification principles and suggest potential improvements to current gameful design methods. Finally, we propose directions for future empirical research aimed to apply this conceptual framework in practice.
\end{abstract}

\section{Introduction}

Goal-setting theory [24, 25] has been used for more than two decades to explain how to motivate people to perform better in work-related tasks by setting and monitoring goals. On the other hand, gamification [8, 16] has recently emerged as a novel, promising approach to enhance people's motivation and engagement with activities, systems, or services. It is defined as "using game design elements in non-game contexts" [8] or as "a process of enhancing a service with affordances for gameful experiences [...] to support users' overall value creation" [16]. Goals are common game elements or motivational affordances employed in gameful design. Nevertheless, little conceptual or empirical research is available that explores the use of gamification as a goal-setting intervention [20]. Seaborn and Fels [39] conducted a systematic review of gamification research and noted the theoretical foundations used in gamification frameworks; goal-setting theory is a notable absence.
Therefore, we decided to conduct a literature review and a conceptual investigation of gamification through the lens of goal-setting theory. This research has four goals: (1) to identify the current uses of goalsetting theory in gamification research; (2) to explain the principles and common elements of gamification within the framework of goal-setting theory; (3) to understand how goal-setting recommendations can be implemented with gamification; and (4) to understand how goal-setting recommendations can improve gameful design.

Goal-setting theory $[24,25]$ is a theory of motivation that aims to explain the causes of people's performance in work-related tasks. It was developed from findings of hundreds of empirical studies and posits that performance is directly related to the goals set by individuals for pursuing. Both the content (the object of an action) and the intensity (the difficulty or the amount of effort required to achieve the goal) are relevant. More specifically, the two core findings from empirical studies that led to the development of goalsetting theory in 1990 were $[24,25]$ :

1. There is a linear relationship between the degree of goal difficulty and performance. The linearity of this relationship was supported in several empirical studies, except when the individual reached the limit of their ability to perform the task or when commitment to a highly difficult goal collapsed.

2. Difficult goals lead to higher performance than no goals at all or abstract goals such as "do your best."

Therefore, goal-setting theory posits that optimal performance is achieved when goals are specific (the objective to accomplish is clear) and difficult (the achievement of the goal requires considerable effort).

After the initial definition of the theory, the extant literature grew with hundreds of empirical studies demonstrating the effects, mechanisms, and moderators of goal setting on increasing performance in workrelated tasks. These studies have been used to inform goal-setting interventions and implementations in organizational settings for decades; but surprisingly, they have been scarcely used to inform gameful design, even when gameful systems or experiences are being developed in organizational environments. To clearly understand and provide evidence of the effects of gam- 
ification in goal setting, many empirical studies will be required to test the effects of different gameful experiences in organizational settings - especially if gameful interventions differ in some way from traditional goal setting ones. However, before these empirical evaluations can be conducted, a theoretical and conceptual framework relating goal-setting concepts with gamification concepts needs to exist. The present work contributes to the creation of this framework. Being able to apply goal-setting theory can lead to an improvement of gameful design practice and of the user's potential to achieve optimal performance in goal-oriented tasks.

The remainder of this work is organized as follows. In Section 2, we review the related works which have tried to connect goal-setting theory and gamification and point out their limitations. In Section 3, we present our main contribution. We begin by reviewing the main constructs of goal-setting theory based on two reviews and summaries by Locke and Latham [24, 25]. Next, for each construct, we review the gamification literature to understand how the theory explains the principles of gamification and how gameful design usually implements each goal-setting construct. Finally, we summarize our findings into a conceptual framework and suggest opportunities for future work towards applying goal-setting theory and gamification together for motivating behaviour change.

\section{Literature Review}

Most gameful design methods include some way of setting goals at both the organizational level as well as the individual level (see reviews by Deterding [7], Mora et al. [29], and Morschheuser et al. [30]). However, none of these methods so far seems to have connected gamification with goal-setting theory. Similarly, Jacobs [17] investigated the implementation of gamification in organizations and noted that goals represent the center of the model. Despite this importance for his model, his work does not investigate the relationship between gamification and goal-setting theory.

Therefore, to accomplish our first research goal, we conducted a systematic literature review to identify the current uses of goal-setting theory in gamification research. We carried out the search using Google Scholar with the search query: "gamification Locke Latham". We used the authors" names instead of "goal setting" because it helped identify papers that were in fact related to goal-setting theory. In a prior attempt to use "gamification goal setting" as the search query, we noted that many results mentioned "goal setting" as a gamification element without any reference to the theory. On the other hand, most citations to the theory referred to one of Locke and Latham's publications. Hence, the search query we used allowed us to identify the papers that in fact cited the theory. Moreover, the inclusion criteria for papers were: publications in English in a peer-reviewed conference or journal or as a book chapter; and only full papers whose main topic was related to gamification and that mentioned goalsetting theory in relation to gamification.

Figure 1 outlines the literature review process. The search returned 302 hits as of August 2017. On an initial examination, 135 papers were discarded for not meeting the inclusion criteria: 80 were not from a peerreviewed conference or journal or from a book chapter, 5 were not a full paper (i.e., they were research in progress or short papers), 8 were not fully available online (or at least could not be obtained by the researchers), and 42 were not written in English. We then screened the title and abstract of the remaining 167 papers and

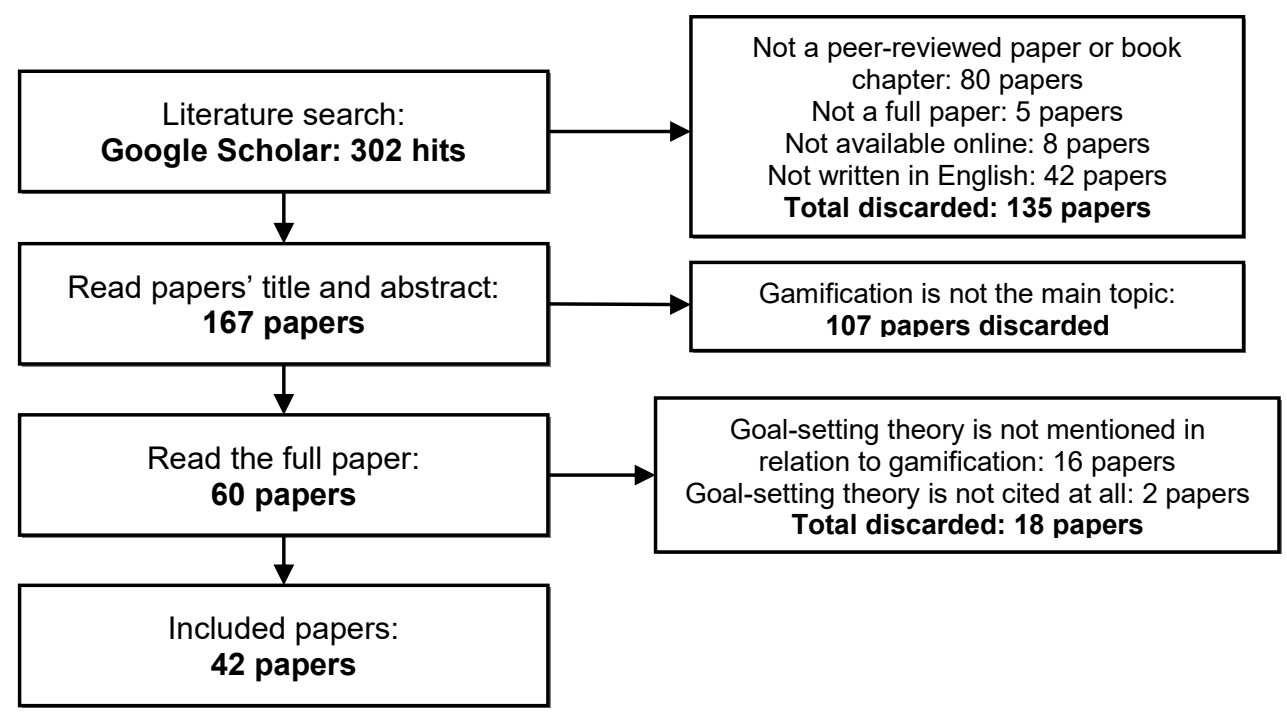

Figure 1. Description of the literature review process. 
discarded 107 of them because their main topic was unrelated to gamification. In this step, we kept papers that clearly addressed a specific gamification element (e.g., badges or leaderboards) even if the title or abstract did not contain the word 'gamification'. Finally, we read the remaining 60 papers and removed 16 papers that did not relate goal-setting theory to gamification (i.e., goal-setting theory was only mentioned in a previous work or background section, without any useful connection to the research) and two papers that did not cite goal-setting theory at all. In the end, 42 papers were selected to be included in the review. We then classified the papers by type of contribution (conceptual/theoretical or empirical study) and extracted information about how goal-setting theory was related to gamification. The complete list of analyzed papers is included in the supplementary material ${ }^{1}$.

Many of the reviewed papers employed goal-setting theory to explain a specific gamification element rather than broad gamification principles. The two elements that appeared more often were badges (13 papers) and leaderboards (6 papers). Rules, goals, challenges, and progress bars also appeared, but less frequently.

On the other hand, some conceptual or theoretical contributions mentioned that goal-setting theory can be used to understand how gamification works in a broader sense. Landers et al. [21] noted that badges and levels can be mechanisms for implementing goal setting, whereas progress bars are mechanisms of direct feedback. Furthermore, they suggested that future research should investigate whether the optimal goal type (a specific, difficult goal) remains the same in gamification, as well as the mechanisms of goal regulation and self-regulation. Richter et al. [36] used goal-setting theory as a theoretical base of incentives and rewards in gamification. They noted that goal-setting can help explain the role of points, challenges, quests, badges, virtual goods, leaderboards, rewards, achievements, and levels in gameful systems. Other conceptual pieces mentioned goal-setting as a theory of motivation for gamification, without more details (e.g., [2, 33]). These works represent a good starting point to understanding gamification through goal-setting theory. However, their analyses are limited to specific elements and do not cover the full range of goal-setting concepts. The present work addresses this gap by providing a comprehensive connection of the most important constructs from both gamification and goal-setting theory.

Regarding empirical evaluation of gameful interventions, many studies in the literature have used goals in a context involving gamification [14]. However, they have not explicitly used goal-setting theory to construct and evaluate their interventions. It seems that

\footnotetext{
${ }^{1}$ http://results.hcigames.com/files/Tondello-HICSS-2018.pdf
}

only a few empirical studies so far have explicitly used goal-setting theory in their conception.

For example, one of these studies was conducted by Hamari and Koivisto [13], investigating social motivations for using a gameful exercise service. Their findings showed that besides helping users set goals, the platform also contributed to goal commitment via social interaction: sharing and being exposed to activities of other users was more likely to promote goal commitment towards challenges in the service.

A few studies $[11,12,23,32]$ investigated the use of badges as a mechanism to implement goal setting and feedback. In general, the results showed that adding badges led to increased user activity. However, it seems that the mere existence of badges is not always sufficient to generate this effect: Hamari [11] found that the increased activity occurred primarily for those users who frequently checked their own badges as well as other users' badges. An explanation for this might be related to goal monitoring and commitment: the existence of goals only influences user activity if the user regularly tracks their performance on achieving the goals (goal feedback) and commits to improving their performance [11].

In addition, a few studies [3, 20, 22] evaluated the effect on task performance of implementing goal setting using leaderboards. Landers et al. [20] noted that goal setting can be an effective theoretical framework to explain the success of leaderboards, that commitment moderates their success as the theory would predict, and that leaderboards increased task performance in a rate similar to a difficult goal. Other gamification elements also evaluated in empirical studies of gamification and goal-setting theory include progress bars [5], goals [40], and challenges [37].

These studies provide promising empirical evidence supporting the use of goal-setting theory to explain gamification phenomena; however, they were focused on a small set of game elements. Therefore, additional studies are required to investigate other gamification elements and mechanisms through the lens of goal-setting theory.

\section{Gamification and goal-setting theory}

Gamification, being derived from games, is inherently a goal-oriented activity [8]. Deterding et al. [8] list "clear goals" as one of the design elements of gamification, whereas Huotari and Hamari [16] list "conflicting goals". In practice, there are many ways by which goals can be implemented in gameful systems; however, there are two common strategies: giving the users clear goals to follow or allowing the users to selfset their own goals. These goals can be explicit, identi- 
fied as goals or quests, for example; or they can also be implicitly presented as outcomes that can be pursued, such as earning badges or achievements or reaching a certain position in a leaderboard. The reviewed literature recognize the following elements as potential mechanisms for goal setting in gamification: badges [9, 10, 27]; leaderboards, levels, and progress bars [21]; rules, goals, challenges, and conflict [19]; points, achievements, and rewards [36]. Although having goals is not a requisite for gamification, goals are present in many gameful applications. Hence, goals are often specific in gamification, consonant to the theory.

In addition to the gameful elements already mentioned in the extant literature, there are many other elements that can be used for goal setting. From a recent list which aggregates gameful design elements from multiple sources [41], we suggest that the following elements can also be used to set clear goals in gamification: boss battles, certificates, collections, exploratory tasks, learning, quests, unlockable or rare content, and unlockable access to advanced features. Thus, there are many possibilities that remain unexplored in implementing the principles of goal-setting theory using gameful design elements.

On the other hand, goal difficulty in gameful systems is dependent on the system's design and the matching between the available goals and the user's skills. Ideally, in a well-designed system, goal difficulty should increase with the user's skill to always provide a challenging activity. This would require the ability to consistently monitor user skill. Several gameful design methods (e.g., [4, 26]) cite flow theory [6] and suggest seeking means to always balance the challenge according to the user's skills to facilitate flow and avoid boredom or anxiety. Hence, if these recommendations are followed, gameful systems should provide difficult enough goals for each user, without making them impossible to achieve due to a lack of ability, congruent to goal-setting theory.

In summary, many gameful applications and systems are based on setting specific and difficult goals. Thus, it is logical to conclude that goal-setting theory can explain why gamification can lead to improved performance in these cases.

Furthermore, goal-setting theory has been able to explain the mechanisms by which specific and difficult goals improve performance, as well as the moderator variables that enhance or attenuate this relationship. In the next subsections, we will describe how these theories can explain the effects of gameful activities.

\subsection{Goal mechanisms}

Goal-setting theory posits that goals affect performance through four mechanisms: choice or direction, effort, persistence, and knowledge or task strategy [24, 25]. Furthermore, self-efficacy has a prominent role in goal-setting theory and there is recent evidence that it can also act as a mediator of goals [25]. In this subsection, we will explore how these mediators can explain and inform gameful design.

The first mechanism that mediates the goalperformance relationship is choice or direction. When an individual has a goal in mind, this helps them orient their attention and effort towards goal-oriented activities and away for those that are irrelevant for the goal $[24,25]$. Besides specific goals, many gameful systems also present the next best actions that, when executed, will lead to accomplishing the goals. This practice is suggested by several gameful design methods $[4,7$, 30]. This helps users focus their choices towards goal accomplishment, thus leading to better performance as postulated by goal-setting theory.

The second mechanism or mediator is effort. Once an individual chooses a goal and chooses to act on it, effort is mobilized in proportion to goal difficulty [24, 25 ]. One of the goals of employing gamification is increasing the user's motivation to carry out the activities and pursue the goals [7]. Thus, in theory, gameful systems could motivate users to exert more effort into pursuing the goals than traditional goal-setting mechanisms. Hence, goal-setting theory would suggest that gamification can lead to increased applied effort because of the increased motivation to pursue the goals. Nonetheless, this effect still needs to be tested and quantified in empirical studies, as well as compared to the effect of traditional goal-setting interventions.

The third mechanism is persistence. Studies have shown that a specific and difficult goal leads people to work longer at the task than a vague or easy goal [24, 25]. Many games encourage users to fail and try again until they master the skills needed to succeed, without fear of serious consequences. Gameful systems can also be designed to provide this safe space for experimentation and learning. This is particularly important when achieving the goal requires learning new skills or improving current skills. However, since gamification sometimes introduces artificial challenges for users to overcome, the designer needs to be careful: if the challenge is not adequately balanced and is perceived as excessively hard by the user, this fact can lead the user to prematurely giving up. For this reason, Deterding [7] suggests designing gameful systems around the challenges that users already face in accomplishing the goals, rather that creating additional artificial challenges. Another example of suggested motivational affordance to avoid the user giving up is glowing choice $[4,41]$, which consists in providing free hints or clues to help the user move forward if they are struggling with a challenge for too long. 
The fourth mechanism is knowledge or task strategy. This means that clear and difficult goals cue the individual to bring upon their extant knowledge or skills required to achieve the goals. If the individual currently lacks the necessary knowledge or skills, this might prevent them from attaining high performance $[24,25]$. As we have previously stated, several gameful design methods suggest balancing the difficulty of challenges according to the user's skill. This can help create a smooth learning curve that allows users to practice the needed skills as they go.

More recent research has also shown that causal attribution for performance (either one believes they are directly responsible for their success in achieving the goals or not) and positive affect (the positive emotions experienced while carrying out the tasks) can influence self-efficacy, and thus, the level of goals that the individual is willing to pursue [25]. In gamification, the feedback mechanisms and the narrative can help users feel they are directly responsible for their success. Moreover, they can also feel they are part of a something larger than themselves, helping they feel selfefficacy in contributing to a larger cause; this is often accomplished by some sort of narrative or theme that depicts the user as the "hero" or as a contributor to an "epic goal" $[4,28]$. This can contribute to increasing both self-efficacy and positive affect. Additionally, gameful systems can potentially afford direct positive emotional experiences because of the game elements with which the user interacts $[11,28]$, further contributing to the effect postulated by goal-setting theory.

\subsection{Goal moderators}

Locke and Latham [24, 25] identified four main moderators of the relationship between goal and performance: ability, task complexity, performance feedback, and goal commitment.

Ability is a moderator because an individual cannot perform in accordance with a goal when they lack the necessary knowledge or skills [25]. Therefore, although performance increases with goal difficulty, this effect is diminished if the goals are perceived as impossible to achieve [25]. Related to this is the moderating effect of task complexity. As the complexity of the task increases, goal effects are dependent on the individual's ability to devise appropriate task strategies [24]. Therefore, goal setting was found to have a stronger effect on tasks that were straightforward for people rather than on complex tasks [24, 25]. Gamification usually solves this problem by breaking challenging goals into smaller ones [4, 7]. This strategy allows the user to progressively acquire the knowledge or skills necessary to accomplish the more difficult goals. Thus, well-designed gameful systems should be able to help adjust the challenges to the user skills, as well as help users learn new skills, leading the user to always feel competent enough to pursue the presented goals. Moreover, there are two gameful elements that can be particularly helpful in temporarily increasing the user's ability to complete a difficult task: glowing choice (providing free hints or clues if the user is stuck on a problem for too long) and power-ups or boosters (a limited-time advantage to make a task easier or allow achieving otherwise impossible goals) [4, 41].

Another moderator of the goal-performance relationship is feedback. Studies have shown that goals and feedback together work better than either one alone $[24,25]$. People need to be able to track their progress toward goal attainment, so they can adjust their strategy and effort accordingly. Together with goals and challenges, feedback is an element which is suggested by most gameful design methods [4, 7, 26, 29, 30]. Landers et al. [21] mentioned that progress bars are one form of feedback commonly employed in gamification. However, there are several other design elements that can be employed in gamification to provide feedback, such as points, levels, achievements or badges, quest completion, leaderboards, avatars, narrative or story, rewards, just to mention a few. Therefore, the empirical evidence collected by goal-setting studies demonstrating the moderating effect of feedback on the goal-performance relationship can also explain why gamification can lead to higher performance.

The last moderator is goal commitment, or the individual's own determination to accomplish the goal. The effects of goal setting on performance only happen if the individual is really trying to accomplish the goal; therefore, commitment is essential [24, 25]. The two main sources of commitment are goal importance and self-efficacy [24, 25]. As discussed in the previous subsection, gameful systems often help the user feel part of a better collaborative effort to reach a common goal, or part of a meaningful effort to improve one's own life, through elements like narrative or story, meaning or purpose, theme, social interaction and collaboration, protection, administrative roles, knowledge sharing, voting mechanisms, or innovation platforms $[4,28,41]$. Therefore, gamification can be particularly effective in increasing one's perception of goal importance. Moreover, Hamari and Koivisto [13] have also identified the social sharing mechanisms present in many gameful systems as facilitators of goal commitment. We have also already discussed how gamification can potentially increase one's self-efficacy. Hence, we can conclude that gameful experiences can potentially increase the individual's motivations towards committing to the suggested goals, thus increasing the chance their performance will also increase as a result. Nonetheless, there is one risk associated with 
gamification: when the motivational elements rely exclusively on extrinsic incentives, such as rewards, users can lose sight of goal importance and focus exclusively on earning the rewards [4]. Therefore, it is important to provide context and meaning to goals to reinforce their importance and foster commitment.

\subsection{Types of goals}

Goal-setting theory has also demonstrated that it is necessary to carefully consider the different types of goals and how each type can affect performance. A distinction has been made between outcome, performance, and process (or learning goals) [25].

Outcome goals refer to the accomplishment of a very specific result [25]. Many examples of goals in gamification are outcome goals. For example, many goals involve completing specific tasks; therefore, the result is well-defined. Challenges, quests, and exploratory tasks are well suited to define outcome goals. An example are the challenges from Barata et al.'s [1] gamified course: theoretical challenges required students to solve problems related to the topics taught in the lectures, whereas lab challenges involved producing creative content using tools and techniques taught in lab classes. Winning the game can also be an outcome goal in some gameful systems.

Performance goals refer to doing well by one's own performance standards [25]. Performance goals are also common in gamification. For example, earning a specific number of points, reaching a specific position in a leaderboard, or completing a specific number of tasks are all examples of performance goals commonly found in gameful systems. Thus, elements like badges, achievements, leaderboards, points, and levels can be helpful in defining performance goals. Some examples are the badges on Hamari's study [12], which established goals related to carrying out certain actions for a predetermined number of times, or the target number of steps per day on Zuckerman and Gal-Oz's gameful physical activity tracker [44].

Process goals (or learning goals) are related to learning new skills. Research has shown that when the individual lacks the necessary skills or knowledge to accomplish a difficult goal, it is better to set a learning goal instead of an outcome or a performance goal [25]. An example of a learning goal can be learning five different ways of completing a task. Learning is an important element in gamification as many design methods suggest steadily increasing the challenge to encourage the user to increase their skills in the process. A few design elements are also specially targeted at helping users learn new skills, such as onboarding or tutorials [4, 26, 41]. Nevertheless, although these game elements are often used to encourage learning, we have not found any literature recommending or using them together with a framing of learning goals. Therefore, we conclude that learning occurs more implicitly than explicitly in gamification. Considering that goal-setting theory has demonstrated the usefulness of explicitly setting learning goals, this might be an important topic for future investigation in gamification research.

Moreover, goal-setting theory specifies that stretch goals are difficult to reach and potentially impossible goals. They are often used as a supplement to required goals and do not need to be attained. Their purpose is to stimulate creative thinking [25]. In games, some optional quests (side quests) can be challenging; however, they are usually meant to be achievable, so they are not near impossible to achieve as a stretch goal should be. In some games, achieving $100 \%$ of the side quests might be nearly impossible due to some of them being incredibly difficult. Similarly, some games provide achievements that are so difficult that only a small percentage of players can achieve them. Hence, acquiring these achievements or completing $100 \%$ of the side quests could be a type of stretch goal in these cases. Some games have an increased difficulty mode that can also be a stretch goal-most players only ever complete the game in the normal difficulty setting, but only the most skilled players will even try to complete everything again in the most difficult setting. Nonetheless, none of these game design ideas seems to be particularly common in gamification; or at least we have not found any literature mentioning the application of these ideas in gameful design. Therefore, this could be an interesting path to explore in future research.

Finally, goal-setting theory also differentiates proximal and distal goals. Proximal goals facilitate the attainment of distal goals [25]. In gamification, as in games, it is a recommended design practice to break larger or distant goals into smaller, proximal goals, to keep the user engaged, improve feedback, and encourage learning $[4,7,26]$. For example, distal goals can be the chapters or levels in the game or in the narrative, which might represent meaningful achievements when completed; whereas proximal goals can be the immediate quests or tasks that the user must perform, and the completion of several of them leads to the completion of the distal goals. Alternatively, completing several chapters or levels might be proximal goals, which lead to the completion of the game (distal goal).

\subsection{Goal orientation}

Goal orientation is an individual trait, which refers to a preference for achievement goals where the focus is on either performance or learning (mastery) [25]. In gamification, the User Types Hexad [42] can be used to understand an individual's preferences for different 
kinds of gameful activities. However, the 'Achiever' user type implies both performance and learning in this model. Similar models developed for the context of games share a similar characteristic [15]. Thus, future studies could investigate if there is a relation between goal orientation and the gamification user types.

\subsection{Setting optimal goals}

The community seems to be reaching a consensus that goals are the most motivating for high performance when they are specific, measurable, attainable, realistic, and time-bound (SMART; [31]). Although the existing gameful design methods do not explicitly reference "SMART goals", their best practices can help with the setting of goals with these characteristics:

- Specific: goals in gamification (e.g., quests, challenges, tasks) usually explain specifically what needs to be done. Moreover, most gameful design methods posit that goals should always be clear and specific (e.g., $[4,7])$.

- Measurable: in gamification, it is always possible to measure when a goal is completed because the definition of a goal must always be accompanied by the respective definition of how to determine when it is completed, so the game can advance.

- Attainable: most gameful design methods suggest that the difficulty of the goals should increase with the user skills; thus, the goals should always be achievable if this recommendation is followed.

- Realistic: the system might not be able to evaluate the user's constraints (which might be external to the system); thus, it might be hard for the system to decide if the goals are realistic.

- Time-bound: some gameful design methods suggest using goals or tasks with time limits [4, 26, 41]. However, this practice does not seem to be particularly common in gamification. Thus, usually, goals defined in gamification do not have a specific time when they need to be completed. Considering that time limit is regarded by the goal-setting literature as an important characteristic of well-defined goals, it would be interesting to investigate if gameful systems could benefit further by setting time-limited goals more often.

\section{Discussion}

In the present work, we have reviewed the relation between goal setting and gamification in the extant literature and introduced a conceptual framework that establishes a relationship between goal-setting theory concepts and gamification concepts and mechanisms. Table 1 summarizes this framework, based on the con- cepts described in the previous section. Regarding the goals which we sought to accomplish with this research, we can establish the following conclusions:

Our first goal was to identify the current uses of goal-setting theory in gamification research. Our literature review identified 42 papers that use goal-setting theory in the context of gamification research. Nonetheless, after analyzing these papers, we observed that most of them employ goal-setting theory to support, explain, or help design specific gamification elements or features. Thus, we were still lacking a comprehensive work establishing ties between the most important gamification and goal-setting principles. Our work has contributed with a new conceptual framework that addresses this gap.

Our second goal was to understand how goalsetting theory can explain the principles and common elements of gamification. We have noted that gamification is often based on setting specific and difficult goals, encouraging users to pursue these goals, and providing constant feedback. Therefore, a gamification implementation that follows these guidelines should be able to satisfy these principles as explained by goalsetting theory. Moreover, we have introduced a probable explanation regarding how gameful experiences activate the mechanisms at work when goal setting is used to improve performance: (1) setting clear goals through gameful elements and encouraging users to pursue them help users focus their attention and efforts towards achieving the goals; (2) gamification can encourage users to fail and try again until they achieve mastery, thus fostering persistence; (3) gamification can help users learn new skills by scaling the challenges according to the users' current abilities; and (4) gameful experiences usually lead to self-attribution of performance, positive affect, and self-efficacy, further enhancing the effect of performance improvement.

Furthermore, we have also explained how gamification can act on the moderator variables that influence the relationship between goals and performance: (1) gameful design guidelines suggest that the system should scale the difficulty and help users acquire new skills, so they would always feel they have the ability to pursue the goals; (2) gameful systems usually provide constant and actionable feedback, which not only informs the users regarding their current performance, but also hints at the potential next actions towards the goals; and (3) gamification can facilitate goal commitment by helping users identify the importance of their goals and by fostering social interactions.

Finally, we have noted that gameful systems usually provide users with both outcome and performance goals. Additionally, they also usually guide users into learning new skills, although this process is not commonly framed as learning goals. Moreover, gameful 
Table 1. Summary of the conceptual framework connecting gamification and goal-setting theory.

\begin{tabular}{|c|c|c|c|}
\hline $\begin{array}{c}\text { Goal setting } \\
\text { principle }\end{array}$ & How it explains gamification & Gameful design guidelines & $\begin{array}{c}\begin{array}{c}\text { Related gameful design } \\
\text { elements }\end{array} \\
\end{array}$ \\
\hline \multicolumn{4}{|c|}{ Basic principles } \\
\hline Specific goals & $\begin{array}{l}\text { Goal specificity is achieved when game- } \\
\text { ful systems use clear goals }\end{array}$ & $\begin{array}{l}\text { Goals should be specific to focus the } \\
\text { user's attention and effort towards } \\
\text { them }\end{array}$ & \multirow{2}{*}{$\begin{array}{l}\text { badges, leaderboards, levels, } \\
\text { progress bars, rules, goals, } \\
\text { challenges, conflict, points, } \\
\text { achievements, rewards, boss } \\
\text { battles, certificates, collections, } \\
\text { exploratory tasks, learning, } \\
\text { quests, unlockable or rare con- } \\
\text { tent or advanced features }\end{array}$} \\
\hline Difficult goals & $\begin{array}{l}\text { User will be faced with difficult goals if } \\
\text { the design follows the recommendation } \\
\text { of adjusting the challenge according to } \\
\text { user skill }\end{array}$ & $\begin{array}{l}\text { Difficult goals should result in better } \\
\text { performance than easy goals; howev- } \\
\text { er, goal difficulty must not exceed } \\
\text { user ability }\end{array}$ & \\
\hline \multicolumn{4}{|c|}{ Mediators } \\
\hline $\begin{array}{l}\text { Choice or } \\
\text { direction }\end{array}$ & $\begin{array}{l}\text { When gameful systems present the next } \\
\text { best task, this helps focus the user's } \\
\text { attention to the goal }\end{array}$ & $\begin{array}{l}\text { Always presenting the user with the } \\
\text { next best task once a goal is reached }\end{array}$ & \\
\hline Effort & $\begin{array}{l}\text { Gamification can lead to increased effort } \\
\text { due to increased motivation }\end{array}$ & - & \\
\hline Persistence & $\begin{array}{l}\text { When gameful systems allow users to } \\
\text { try again after a failure, they encourage } \\
\text { persistence }\end{array}$ & $\begin{array}{l}\text { Support the user in trying again until } \\
\text { they master the skills necessary to } \\
\text { achieve a goal. Provide aid in case of } \\
\text { difficulty to avoid desistance }\end{array}$ & challenges, glowing choice \\
\hline Task strategy & $\begin{array}{l}\text { When gameful systems balance the } \\
\text { difficult according to the user's skill, } \\
\text { they allow the user to practice the skills } \\
\text { necessary to complete harder challenges }\end{array}$ & $\begin{array}{l}\text { Balance the difficulty of the challenge } \\
\text { to the user skill and give time for the } \\
\text { user to practice the necessary skills } \\
\text { before introducing harder tasks }\end{array}$ & challenges \\
\hline Self-efficacy & $\begin{array}{l}\text { Feedback and purpose elements can help } \\
\text { the user feel they are responsible for } \\
\text { their success and the success of a larger } \\
\text { cause }\end{array}$ & $\begin{array}{l}\text { Provide feedback that allows the user } \\
\text { to feel responsible for their success; } \\
\text { provide a larger meaning for their } \\
\text { achievements }\end{array}$ & $\begin{array}{l}\text { feedback, badges, achievements, } \\
\text { progress bars, levels, points, } \\
\text { certificates, narrative, humanity } \\
\text { hero, meaning or purpose }\end{array}$ \\
\hline \multicolumn{4}{|c|}{ Moderators } \\
\hline Ability & \multirow{2}{*}{$\begin{array}{l}\text { When gameful applications break com- } \\
\text { plex tasks in small pieces, they help in } \\
\text { reducing task complexity and increasing } \\
\text { the user's ability to complete them }\end{array}$} & \multirow{2}{*}{$\begin{array}{l}\text { Divide complex tasks into smaller } \\
\text { pieces that are achievable at the user's } \\
\text { current ability level; it the user is } \\
\text { stuck at a task, provide means to help } \\
\text { them complete it }\end{array}$} & \multirow[b]{2}{*}{$\begin{array}{l}\text { guests, goals, tasks, glowing } \\
\text { choice, power-ups or boosters }\end{array}$} \\
\hline $\begin{array}{l}\text { Task } \\
\text { complexity }\end{array}$ & & & \\
\hline $\begin{array}{l}\text { Progress } \\
\text { feedback }\end{array}$ & $\begin{array}{l}\text { Many gameful systems provide some } \\
\text { form of feedback on goal completion, } \\
\text { which has been shown to increase per- } \\
\text { formance }\end{array}$ & $\begin{array}{l}\text { Provide meaningful feedback, which } \\
\text { the user can employ to gauge their } \\
\text { progress towards goal attainment }\end{array}$ & $\begin{array}{l}\text { points, levels, badges, achieve- } \\
\text { ments, quest completion, lead- } \\
\text { erboards, avatars, narrative or } \\
\text { story, rewards }\end{array}$ \\
\hline $\begin{array}{l}\text { Goal } \\
\text { commitment }\end{array}$ & $\begin{array}{l}\text { Gamification can help the user under- } \\
\text { stand the task importance and increase } \\
\text { self-efficacy }\end{array}$ & $\begin{array}{l}\text { Provide a context or meaning so the } \\
\text { user can understand the importance of } \\
\text { the task and feel committed to it }\end{array}$ & $\begin{array}{l}\text { narrative, story, meaning, pur- } \\
\text { pose, humanity hero, social } \\
\text { network and collaboration }\end{array}$ \\
\hline \multicolumn{4}{|c|}{ Types of goals } \\
\hline Outcome goals & $\begin{array}{l}\text { Goals related to completing specific } \\
\text { tasks in gameful systems }\end{array}$ & - & $\begin{array}{l}\text { challenges, quests, and explora- } \\
\text { tory tasks }\end{array}$ \\
\hline $\begin{array}{l}\text { Performance } \\
\text { goals }\end{array}$ & $\begin{array}{l}\text { Goals that require the user to reach } \\
\text { certain performance level or complete a } \\
\text { task a certain number of times }\end{array}$ & - & $\begin{array}{l}\text { badges, achievements, leader- } \\
\text { boards, points, and levels }\end{array}$ \\
\hline Process goals & \multicolumn{2}{|l|}{ Topic open for future investigation } & learning \\
\hline Stretch goals & \multicolumn{2}{|l|}{ Topic open for future investigation } & achievements \\
\hline SMART goals & $\begin{array}{l}\text { Goals seem to be specific, measurable, } \\
\text { and attainable in many gameful systems. } \\
\text { Realistic and time-bound goals are yet } \\
\text { to be further explored }\end{array}$ & $\begin{array}{l}\text { Following the recommendation, goals } \\
\text { in gameful systems should be specific, } \\
\text { measurable, attainable, realistic, and } \\
\text { time-bound for optimal performance }\end{array}$ & \\
\hline
\end{tabular}

systems can also provide users with both proximal and distal goals, showing how the attainment of the proximal goals will help accomplish the distal goals.

Our third goal was to understand how goal-setting recommendations can be implemented with gamification. Our literature review revealed a few initial attempts of studying the implementation of goal setting with gameful elements such as badges, leaderboards, clear goals, and social interactions. Nevertheless, there are many additional potential means to implement goal setting in gamification, which were not specifically studied yet. We have suggested some of these means in the previous section and summarized them in Table 1. Moreover, by presenting this conceptual framework, we also encourage other researchers to consider novel means of implementing goal setting through gamification and conduct additional empirical studies to verify how these mechanisms will work in practice. 
Finally, our last goal was to understand how goal setting recommendations can improve gameful design. We have summarized in Table 1 some design guidelines that can be taken into consideration in gamification based on goal-setting theory. Additionally, through our conceptual framework, we have highlighted that learning goals and stretch goals are two types of goals that are yet not commonly employed in traditional gameful systems. Furthermore, we have also noted that time limit is a design element which is not frequent in gameful systems, and could be an interesting element to consider since goal-setting theory states that time-bound goals tend to be more effective. In addition, we could not identify clear discussions in the gamification literature related to setting realistic goals as posited by goal-setting theory. Thus, this review is also a potential improvement to gameful design methods that provide the theoretical foundation for further investigation into this area.

\subsection{Opportunities for future work}

Several opportunities arise for empirical works investigating how the relationship between goal-setting concepts and gamification concepts works in practice.

In the most basic form, future research can propose new ways to implement goal-setting interventions with gamification, focusing particularly on the implementation of goal specificity, goal intensity, and feedback. Following that, empirical studies can investigate the overall effects of gamification on task performance. Next, studies specifically constructed to measure the intensity of the mediating variables during the gameful experience would be invaluable to understand if these mechanisms work in gameful experiences in a similar way than in traditional goal-setting activities.

Furthermore, studies focused on the moderator variables could try to variate the type of game design elements in a gameful system and measure the effects on goal commitment, as well as perceived feedback and ability, and try to establish how much these variations influence the overall task performance. Similarly, specific studies could variate the kinds of goals employed in gameful systems and verify if different types of goals lead to similar or different overall performance, mediating, or moderating effects.

Moreover, there are a few concepts from goalsetting theory that have been scarcely explored in the gamification literature, namely learning and stretch goals, time-bound goals, and realistic goals; as well as the role of self-regulation to goal performance, which we did not explore in this paper. Therefore, future work could focus on novel implementations of these goal-setting recommendations in gameful design and evaluating the potential effects on the outcomes.
Finally, there are currently many concerns voiced in the literature regarding how goal setting [34, 38, 43] and gamification $[2,18,35]$ can be used to encourage unethical behaviours. Thus, further investigation on how these concerns are related and guidelines to avoid the dark effects of gamification informed by goalsetting theory is an important topic for future research.

\section{Acknowledgments}

This research was funded by the CNPq, Brazil, University of Waterloo, SSHRC (895-2011-1014, IMMERSe), NSERC (RGPIN-418622-2012), CFI (35819), and Mitacs with FlourishiQ Inc. (IT07255).

\section{References}

[1] G. Barata, S. Gama, J. Jorge, and D. Gonçalves, "Studying student differentiation in gamified education: A longterm study," Computers in Human Behavior 71, 2017, pp. 550-585.

[2] R. C. Callan, K. N. Bauer, and R. N. Landers, "How to avoid the dark side of gamification: Ten business scenarios and their unintended consequences," in T. Reiners and L. C. Woods (eds.), Gamification in Education and Business, Springer, 2015, pp. 553-568.

[3] S. Chernbumroong, P. Sureephong, and O. Muangmoon, "The effect of leaderboard in different goal-setting levels," in International Conference on Digital Arts, Media and Technology (ICDAMT), IEEE, 2017, pp. 230-234.

[4] Y. Chou, Actionable Gamification: Beyond points, badges, and leaderboards. Octalysis Media, USA, 2015.

[5] D. Codish and G. Ravid, "Academic course gamification: The art of perceived playfulness," Interdisciplinary Journal of E-Learning and Learning Objects 10, 2014, pp. 131-151.

[6] M. Csikszentmihalyi, Flow: The psychology of optimal experience. Harper Perennial, New York, NY, 1990.

[7] S. Deterding, "The lens of intrinsic skill atoms: A method for gameful design", Human-Computer Interaction, 30 (3-4), Taylor \& Francis, 2015, pp. 294-335.

[8] S. Deterding, D. Dixon, R. Khaled, and L. E. Nacke, "From game design elements to gamefulness: Defining 'Gamification'", Proceedings of MindTrek'11, ACM, 2011.

[9] J. R. Fanfarelli and R. McDaniel, "Digital badges for deliberate practice: Designing effective badging systems for interactive communication scenarios," in Proceedings of the $33^{\text {rd }}$ Annual International Conference on the Design of Communication, ACM, 2015, p. 49.

[10] J. Fanfarelli, S. Vie, and R. McDaniel, "Understanding digital badges through feedback, reward, and narrative: a multidisciplinary approach to building better badges in social environments," Communication Design Quarterly Review 3 (3), 2015, pp. 56-60.

[11] J. Hamari. "Transforming homo economicus into homo ludens: A field experiment on gamification in a utilitarian peer-to-peer trading service", Electronic Commerce Research and Applications, 12, Elsevier, 2013, pp. 236-245. 
[12] J. Hamari, "Do badges increase user activity? A field experiment on the effects of gamification", Computers in Human Behavior, 71, Elsevier, 2017, pp. 469-478.

[13] J. Hamari and J. Koivisto, "Social motivations to use gamification: An empirical study of gamifying exercise", in $21^{\text {st }}$ European Conference on Information Systems, 2013.

[14] J. Hamari, J. Koivisto, and H. Sarsa, "Does gamification work? - A literature review of empirical studies on gamification", Proc. $47^{\text {th }}$ Annual Hawaii International Conference on System Sciences (HICSS), IEEE, 2014, pp. 3025-3034.

[15] J. Hamari and J. Tuunanen, "Player types: A metasynthesis", Transactions of the Digital Games Research Association, 1 (2), 2014.

[16] K. Huotari and J. Hamari, "A definition for gamification: Anchoring gamification in the service marketing literature", Electronic Markets, 21 (1), Springer, 2017, pp. 21-31.

[17] H. Jacobs, Gamification: A framework for the workplace, M.Sc. Dissertation, University of Liverpool, 2013.

[18] T. W. Kim and K. Werbach, "More than just a game: ethical issues in gamification," Ethics and Information Technology 18 (2), 2016, pp. 157-173.

[19] R. N. Landers, M. B. Armstrong, and A. B. Collmus, "How to Use Game Elements to Enhance Learning: Applications of the Theory of Gamified Learning," in M. Ma and A. Oikonomou (Eds.), Serious Games and Edutainment Applications, Vol. 2, Springer, 2017, pp. 457-483.

[20] R. N. Landers, K. N. Bauer, and R. C. Callan, "Gamification of task performance with leaderboards: A goal setting experiment", Computers in Human Behavior, 71, Elsevier, 2017, pp. 508-515.

[21] R. N. Landers, K. N. Bauer, R. C. Callan, and M. B. Armstrong, "Psychological theory and the gamification of learning", in T. Reiners and L. C. Woods (eds.), Gamification in Education and Business, Springer, 2015, pp. 165-186.

[22] R. N. Landers and A. K. Landers, "An empirical test of the theory of gamified learning: The effect of leaderboards on time-on-task and academic performance," Simulation \& Gaming, 45 (6), 2014, pp. 769-785.

[23] X. Liu, M. Schuckert, and R. Law, "Online incentive hierarchies, review extremity, and review quality: Empirical evidence from the hotel sector," Journal of Travel \& Tourism Marketing 33 (3), 2016, pp. 279-292.

[24] E. A. Locke and G. P. Latham, "Building a Practically Useful Theory of Goal Setting and Task Motivation: A 35Year Odyssey," American Psychologist, 57 (9), 2002, pp. 705-717.

[25] E. A. Locke and G. P. Latham (eds.), New developments in goal setting and task performance, Routledge, New York, NY, 2013.

[26] A. Marczewski, Even ninja monkeys like to play: Gamification, game thinking \& motivational design, CreateSpace Independent Publishing Platform, UK, 2015.

[27] R. McDaniel and J. Fanfarelli, "Building better digital badges: Pairing completion logic with psychological factors," Simulation \& Gaming 47 (1), 2016, pp. 73-102.

[28] J. McGonigal, SuperBetter: A revolutionary approach to getting stronger, happier, braver and more resilient, Penguin Books, 2015.

[29] A. Mora, D. Riera, C. Gonzalez, and J. Arnedo-Moreno, "Gamification: a systematic review of design frameworks," Journal of Computing in Higher Education, 2017, pp. 1-33.
[30] B. Morschheuser, K. Werder, J. Hamari, and J. Abe, "How to gamify? A method for designing gamification", Proceedings of the $50^{\text {th }}$ Annual Hawaii International Conference on System Sciences (HICSS), IEEE, 2017.

[31] G. B. Moskowitz and H. Grant, The psychology of goals, Guilford Press, New York, NY, 2009.

[32] T. Mutter and D. Kundisch, "Behavioral mechanisms prompted by badges: The goal-gradient hypothesis," in Proc. $35^{\text {th }}$ International Conference on Information Systems, 2014.

[33] B. K. Neeli, "Gamification in the enterprise: Differences from consumer market, implications, and a method to manage them," in T. Reiners and L. C. Woods (eds.), Gamification in Education and Business, Springer, 2015, pp. 489-511. [34] L. D. Ordóñez, M. E. Schweitzer, A. D. Galinsky, and M. H. Bazerman, "Goals gone wild: The systematic side effects of overprescribing goal setting," The Academy of Management Perspectives 23 (1), 2009, pp. 6-16.

[35] M. Raftopoulos, "Towards gamification transparency: A conceptual framework for the development of responsible gamified enterprise systems," Journal of Gaming \& Virtual Worlds, 6 (2), 2014, pp. 159-178.

[36] G. Richter, D. R. Raban, and S. Rafaeli, "Studying gamification: The effect of rewards and incentives on motivation", in T. Reiners and L. C. Woods (eds.), Gamification in Education and Business, Springer, 2015, pp. 21-46.

[37] J. Schrammel, S. Prost, E. Mattheiss, E. Bothos, and M. Tscheligi, "Using Individual and Collaborative Challenges in Behavior Change Support Systems: Findings from a TwoMonth Field Trial of a Trip Planner Application," in International Conference on Persuasive Technology, Springer, 2015, pp. 160-171.

[38] M. E. Schweitzer, L. Ordóñez, and B. Douma. "The dark side of goal setting: The role of goals in motivating unethical decision making," in Academy of Management Proceedings, 2002 (1), pp. B1-B6.

[39] K. Seaborn and D. I. Fels, "Gamification in theory and action: A survey", International Journal of Human-Computer Studies, 74, Elsevier, 2014, pp. 14-31.

[40] M. Tan and K. F. Hew, "Incorporating meaningful gamification in a blended learning research methods class: Examining student learning, engagement, and affective outcomes," Australasian Journal of Educational Technology, 32 (5), 2016.

[41] G. F. Tondello, A. Mora, and L. E. Nacke, "Elements of Gameful Design Emerging from User Preferences," in Proceedings of the 2017 Annual Symposium on ComputerHuman Interaction in Play (CHI PLAY '17), ACM, 2017.

[42] G. F. Tondello, R. R. Wehbe, L. Diamond, M. Busch, A. Marczewski, and L. E. Nacke, "The gamification user types Hexad scale", Proc. of the 2016 Annual Symposium on Computer-Human Interaction in Play (CHI PLAY '16), ACM, 2016, pp. 229-243.

[43] D. T. Welsh and L. D. Ordóñez, "The dark side of consecutive high performance goals: Linking goal setting, depletion, and unethical behavior," Organizational Behavior and Human Decision Processes, 123 (2), 2014, pp. 79-89.

[44] O. Zuckerman and A. Gal-Oz, "Deconstructing gamification: evaluating the effectiveness of continuous measurement, virtual rewards, and social comparison for promoting physical activity," Personal and Ubiquitous Computing 18 (7), 2014, pp. 1705-1719. 